\title{
Efficacy and Safety of Percutaneous Microwave Ablation and Cementoplasty in the Treatment of Painful Spinal Metastases and Myeloma
}

\author{
(D) M.A. Khan, (D) G. Deib, (D)B. Deldar, (D)A.M. Patel, and (D).S. Barr
}

\begin{abstract}
BACKGROUND AND PURPOSE: Painful spinal metastases are a common cause of cancer-related morbidity. Percutaneous ablation presents an attractive minimally invasive alternative to conventional therapies. We performed a retrospective review of 69 patients with 102 painful spinal metastases undergoing microwave ablation and cementoplasty to determine the efficacy and safety of this treatment.
\end{abstract}

MATERIALS AND METHODS: Procedures were performed between January 2015 and October 2016 with the patient under general anesthesia using image guidance for 102 spinal metastases in 69 patients in the following areas: cervical $(n=2)$ ), thoracic $(n=50)$, lumbar ( $n=34)$, and sacral ( $n=16)$ spine. Tumor pathologies included the following: multiple myeloma $(n=10)$, breast ( $n=27)$, lung $(n=12)$, thyroid $(n=6)$, prostate $(n=$ 5), colon $(n=4)$, renal cell $(n=3)$, oral squamous cell $(n=1)$, and adenocarcinoma of unknown origin $(n=1)$. Procedural efficacy was determined using the visual analog scale measured preprocedurally and at 2-4 weeks and 20-24 weeks postprocedure. Tumor locoregional control was assessed on follow-up cross-sectional imaging. Procedural complications were recorded to establish the safety profile.

RESULTS: The median ablation time was 4 minutes 30 seconds \pm 7 seconds, and energy dose, $4.1 \pm 1.6 \mathrm{~kJ}$. Median visual analog scale scores were the following: $7.0 \pm 1.8$ preprocedurally, $2 \pm 1.6$ at $2-4$ weeks, and $2 \pm 2.1$ at $20-24$ weeks. Eight patients died within 6 months following the procedure. Follow-up imaging in the surviving patients at 20-24 weeks demonstrated no locoregional progression in $59 / 61$ patients. Two complications were documented (S1 nerve thermal injury and skin burn).

CONCLUSIONS: Microwave ablation is an effective and safe treatment technique for painful spinal metastases. Further studies may be helpful in determining the role of microwave ablation in locoregional control of metastases.

ABBREVIATIONS: MWA = microwave ablation; ODI = Oswestry Disability Index; Pre = preprocedure; RT = radiation therapy; VAS = visual analog scale

B one metastases are common in patients with advanced cancer and are the greatest contributor to cancer-related pain, with severe pain in up to $75 \%$ of patients with bone metastases. This pain is often unremitting and may severely affect the patient's quality of life. ${ }^{1}$ Patients with metastatic disease are often undertreated for pain. ${ }^{2-4}$ Various treatment options exist for patients with painful spinal metastases, including surgery, radiation therapy, and percutaneous interventions. Historically, radiation therapy has been the standard of care for painful osseous metastases. However, approximately $40 \%$ of treated patients do not experience adequate pain relief. ${ }^{5,6}$ In addition, almost half of the re-

Received November 10, 2017; accepted after revision March 6, 2018.

From the Department of Radiology (M.A.K., G.D.), John Hopkins University, Baltimore, Maryland; St. George's University of London (B.D.), London, UK; Departments of Radiology (A.M.P.) and Orthopedics (J.S.B.), University of Mississippi Medical Centre, Jackson, Mississippi.

Please address correspondence to Gerard Deib, MD, Johns Hopkins Hospital and Health System, 601 N Caroline St, Baltimore, MD 21287; e-mail: gdeib1@ jhmi.edu; @gerarddeib

http://dx.doi.org/10.3174/ajnr.A5680 maining patients have recurrent pain at a median of 16 weeks following treatment. ${ }^{5}$

Management of metastatic spine disease requires multidisciplinary input. Treatment options include not only continually evolving medical therapy regimens, surgical techniques, and radiation technologies but also emerging minimally invasive interventions. Treatment recommendations should be based on collaborative recommendations of specialists as outlined by the Metastatic Spine Disease Multidisciplinary Working Group, which has provided a consensus document detailing the evidence supporting their algorithms.

Image-guided ablative therapies demonstrate potential advantages compared with surgery and radiation therapy, including reduced morbidity, lower procedural cost, suitability for real-time imaging guidance, the ability to perform therapy in an outpatient setting, synergy with other cancer treatments, repeatability, and short procedural time. ${ }^{8-10}$ Ablation (alone or in combination with cementoplasty) can achieve a number of objectives: palliative pain control, skeletal stabilization, and tumor control. In most 
cases, an improvement in quality of life and prevention of morbidity would be the primary goals, rather than tumor control, especially in sick patients with limited life expectancy and poor functional status, who are often poor surgical candidates. ${ }^{11}$

An ever-expanding array of percutaneous ablation technologies is being used in the treatment of painful neoplastic lesions. These modalities include cryoablation, ethanol ablation, laser ablation, MRI-guided focused sonography ablation, and radiofrequency ablation. ${ }^{8,10-12}$

Microwave ablation (MWA) offers several potential advantages over other ablative modalities that may increase its effectiveness in the treatment of tumors, including larger tumor ablation volumes with a single probe, faster ablation times, improved convection profile, and optimal heating of necrotic masses. MWA has consistently higher intratumoral temperatures than other heatbased therapies. Like cryoablation, MWA can be performed with multiple applicators. ${ }^{13-16}$ However, MWA is a relatively new innovation, and literature demonstrating its clinical efficiency in treating spinal tumors is relatively sparse, with only 2 retrospective studies published to date (describing 20 and 37 lesions in 17 and 35 patients, respectively). ${ }^{17,18}$ The authors therefore aimed to present a larger retrospective series to demonstrate the efficacy and safety of microwave ablation and cementoplasty.

In our practice, polymethylmethacrylate is administered following ablation of spinal tumors. This is to prevent pathologic fractures (either because of metastatic disease directly or following ablative therapy), which may be a significant source of further pain from metastatic disease. In addition to alleviating pain, this may be helpful in preventing associated morbidities such as progressive kyphosis and respiratory compromise or damage to adjacent spinal nerve roots.

The authors report the results of a retrospective review to evaluate the safety and efficacy of MWA and cementoplasty for treating painful spinal metastases. To our knowledge, this series represents the largest study yet published in the literature and serves to confirm or refute findings from previously published smaller series.

We hypothesized that MWA ablation and cementoplasty would result in markedly reduced pain scores. We further hypothesized that a substantial proportion of our patients would demonstrate no evidence of disease progression on 6-month follow-up cross-sectional imaging.

The purpose of this study was to determine whether treatment of metastatic disease to the vertebral body with MWA and cementoplasty would significantly decrease visual analog scale (VAS) pain scores at 6 months. The secondary purpose of this study was to determine disease progression in the treated vertebral body in patients with oligometastatic disease at 6 months with cross-sectional imaging.

\section{MATERIALS AND METHODS}

Full Johns Hopkins Hospital institutional review board approval was obtained for retrospective analysis. Informed consent for the study was waived and Health Insurance Portability and Accountability Act compliance was guaranteed. Medical records, including demographics and pain scores, were obtained and reviewed.

Efficacy of treatment was defined by accomplishing primary and secondary objectives. The primary objective was pain reduc- tion after microwave ablation and cementoplasty. The secondary objective was effective disease control, based on the absence of locoregional disease progression on follow-up cross-sectional imaging evaluation. Complications were reviewed in this cohort of patients to assess the safety of the procedure.

\section{Patient Information}

A search was performed using the keywords "microwave ablation," "cementation," "cementoplasty," "kyphoplasty," and "vertebroplasty" on all files in the Electronic Medical Record of our institution from January 2015 to October 2016. On the basis of this search and application of the inclusion and exclusion criteria detailed below, appropriate records were accessed.

A total of 105 patients were found in the search of our institution. These patients had all been screened at the multidisciplinary conference. After we applied the inclusion and exclusion criteria, 69 patients (36 men, 33 women) with spinal metastases treated with microwave ablation and cementoplasty from January 2015 to October 2016 were included in this retrospective review. The mean age of the patients was 56 .

\section{Inclusion Criteria}

We included the following:

A) Patients with intractable pain (VAS $>4$ ) from solitary or multiple sites of disease that resulted in a return visit to the oncologist (intractable pain was defined as unrelenting pain despite treatment with narcotic anesthesia).

B) Patients who either

1) Had persistent or recurrent pain after radiation therapy (RT),

2) Were not candidates for RT,

3) Had declined RT,

4) Had tumor considered percutaneously accessible by imaging.

\section{Exclusion Criteria}

We excluded the following:

A) Patients with an alternative explanation for pain based on correlation between clinical presentation and spine MR imaging,

B) Concurrent systemic illness,

C) Tumors with retropulsion of the posterior cortices, epidural extension, and/or cord compression,

D) Patients who had tumors whose margins approximated nerve roots or the spinal canal.

Twenty-eight patients who had undergone prior radiation therapy with continued pain were included in the study.

All patients had prior cross-sectional imaging (CT, MR imaging, and/or PET/CT). Sixty-nine patients had complete assessment of their pain in the interventional radiology clinic of our department using the visual analog scale pain score preprocedurally and at $2-3$ weeks $(n=69)$ and $20-24$ weeks $(n=61)$ postprocedure. In addition, 52 patients were assessed using the Oswestry Disability Index (ODI) score chart before the procedure and at similar intervals following it, with 17 patients refusing to use the ODI preset questionnaire for ODI determination.

Patients had been deemed appropriate for image-guided ablation and cementation in the multidisciplinary conference after discussion and review of cross-sectional imaging, which included a combination of CT, PET/CT, and MR imaging. All cross-sec- 
tional studies were evaluated by a noninterventionalist, boardcertified, fellowship-trained neuroradiologist and were subsequently reviewed by a board-certified, fellowship-trained spine interventional radiologist at the multidisciplinary tumor board.

On the basis of cross-sectional CT imaging, lesions were classified into 65 lytic, 13 sclerotic, and 24 mixed lytic/sclerotic. The tumor area ranged between 0.75 to $15.0 \mathrm{~cm}^{2}$ (mean, $3.6 \pm 2.2$ $\mathrm{cm}^{2}$ ) based on CT and MR imaging review by the interventional radiologist. Figure 1 demonstrates an example of a lytic osseous metastasis in a patient with metastatic breast carcinoma.

\section{Procedural Details}

Microwave ablation was performed using the AveCure microwave ablation system (MedWaves, San Diego, California) under CT (16-slice Somatom Sensation; Siemens, Erlangen, Germany) or fluoroscopic (Axiom Artist dBA Bi-Plane; Siemens) guidance. Most procedures were performed as outpatient procedures $(n=$ 63 ; 91.3\%) with 4-hour postprocedural observation. Patients whose lesions were within $5 \mathrm{~mm}$ of nerve roots $(n=6 ; 8.7 \%)$ were observed for 23 hours. All procedures were performed with the patient under general anesthesia and prone. Lesions were measured in 3 planes on cross-sectional imaging before the procedure. These measurements were then used as a basis for calculating the volume (and correlating energy deposition and time parameters) for ablation as detailed in Table 1. The cross-sectional imaging

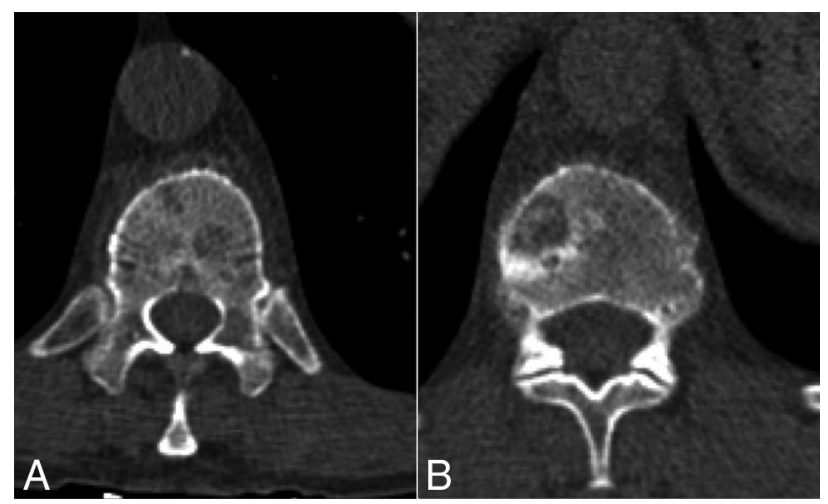

FIG 1. Axial $C T$ images with the patient supine demonstrate lytic osseous metastasis in the $T 11(A)$ and $T 12(B)$ vertebral bodies in a 60-yearold woman with metastatic breast carcinoma. was used in procedural planning, including making note of the proximity of tumoral margins to critical anatomic landmarks.

Local anesthesia (lidocaine hydrochloride $1 \%$ ) was administered with a 3.5 -inch 22 -g spinal needle used to infiltrate the periosteum to ease the postprocedural pain followed by soft-tissue blunt dissection. An 11-g iVAS access cannula (Stryker Neurovascular, Kalamazoo, Michigan) was inserted via a posterior or posterolateral approach (either transpedicular or transcostovertebral) under image guidance and was positioned at the proximal edge of the tumor. A 13-g hand drill was then coaxially inserted into the tumor and advanced to its anterior edge. Once this position was confirmed, core biopsies were obtained and sent to the laboratory.

Subsequently, a single 14- or 16-g Avecure microwave ablation antenna (MedWaves, 1.8-mm, 20-cm-long) was coaxially inserted into the tumor. Placement of the hand drill and the ablation antenna is demonstrated in Fig 2. The size of the ablation antenna was determined on the basis of the calculated target lesion size, with the ablation zone calculated as $2 \mathrm{~mm}$ beyond the actual size of the target lesion to achieve adequate control. To calculate the appropriate cutoff temperature and energy deposition, we took the following approach: anteroposterior, lateral, and transverse measurements of the probe position relative to the vertebral margins. These measurements were then used to determine the appropriately sized antenna. Energy in kilojoules and temperature in centigrade were subsequently calculated using the vendor's standard algorithm. The team was then able to achieve these end points with our ablation.

A 13-g Trovex curved needle (Stryker) was used to access lesions along the posterior aspect of vertebral body; then, a 16-g 90-cm flexible Avecure microwave antenna (Medwaves) was advanced into an adequate position for ablation. An automated drill (11-g Arrow On-Control; Teleflex, Morrisville, North Carolina) and a biopsy cannula were used to access mixed and dense sclerotic lesions with subsequent placement of the microwave probe.

For fluoroscopically guided procedures in which there was a small ablation, conebeam CT (InSpace Dyna CT; Siemens) was performed to confirm the antenna position through the lesion. Where there were large lesions encompassing two-thirds of the vertebral body, a bipedicular approach was used with overlapping ablation zones. For CT-guided procedures, the antenna position was always confirmed under CT. The burn size was overestimated by only $2 \mathrm{~mm}$ in all directions in patients with oligometastatic disease (to achieve better disease control). However, the accuracy

Table 1: Tabular results of Mann-Whitney $U$ paired tests between VAS and ODI data collected Pre and at 2-4 and 20-24 weeks, respectively

\begin{tabular}{llllc}
\hline \multicolumn{1}{c}{ Table Analyzed } & $\begin{array}{c}\text { Mann-Whitney } \\
\text { Test of } \\
\text { VAS Pre-2/4 weeks }\end{array}$ & $\begin{array}{c}\text { Mann-Whitney } \\
\text { Test of VAS } \\
\text { Pre-20/24 weeks }\end{array}$ & $\begin{array}{c}\text { Mann-Whitney } \\
\text { Test of ODI } \\
\text { Pre-2/4 weeks }\end{array}$ & $\begin{array}{c}\text { Mann-Whitney } \\
\text { Test of ODI } \\
\text { Pre-20/24 weeks }\end{array}$ \\
\hline $\begin{array}{l}\text { Column B } \\
\text { versus }\end{array}$ & VAS 2-4 weeks & VAS 20-24 weeks & ODI 2-4 weeks & ODI 20-24 weeks \\
$\begin{array}{l}\text { Column A } \\
\text { Mann Whitney test }\end{array}$ & VAS Pre & VAS Pre & ODI Pre & ODI Pre \\
$\quad$ P value & $<.0001$ & $<.0001$ & $<.0001$ & $<.0001$ \\
$\quad$ Sum of ranks in columns A and B & 5526,1978 & 5478,2025 & 2665,1252 & 2672,1244 \\
$\quad \begin{array}{l}\text { Mann-Whitney U } \\
\text { Median of column A }\end{array}$ & 86.5 & 134 & 261.5 & 254 \\
Median of column B & $7, n=61$ & $7, n=61$ & $46, n=44$ & $46, n=44$ \\
$\begin{array}{l}\text { Difference: actual } \\
\text { Difference: Hodges-Lehmann }\end{array}$ & $2, n=61$ & $2, n=61$ & $24, n=44$ & $24, n=44$ \\
Exact 95.01\% Cl of difference & -5 & -5 & -22 & -22 \\
\hline
\end{tabular}




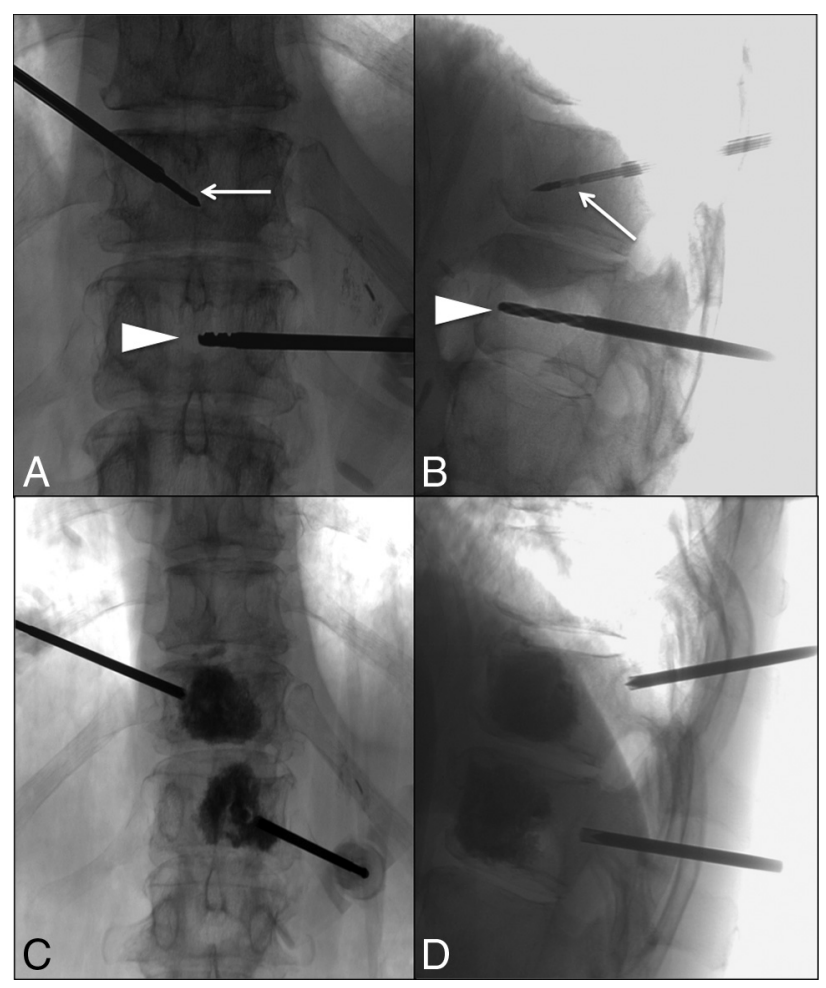

FIG 2. Intraprocedural anteroposterior $(A)$ and lateral (B) fluoroscopic images of T11- and T12-level microwave ablation. A microwave ablation probe (arrow) and a manual drill (arrowhead) have been advanced through access cannulas into the anterior aspect of the TI1 and $T 12$ vertebral bodies, respectively. Anteroposterior $(C)$ and lateral (D) fluoroscopic images of the TT1 and TT2 vertebral bodies post-microwave ablation and cement augmentation. The access cannulas have been retracted into the pedicles.

of the gross extent of induced coagulation was limited by both spatial and contrast resolution to approximately $2-3 \mathrm{~mm}$, and imaging findings are only a rough guide to the success of the ablation therapy because microscopic foci of residual disease cannot be expected to be identified with standard imaging.

Thermocouples were not placed in our series because lesions with a breach of the posterior cortex were excluded from the study, but whenever the ablation zone was close to the neural element $(<5 \mathrm{~mm})$, we used repeat short ablation cycles to control diffusion of the heat zone without decreasing the effectiveness of ablation, a technique used by the spine interventionalist. ${ }^{19}$ However, use of thermocouples and somatosensory evoked potentials/ motor-evoked potentials monitoring is advised to avoid thermal injury to the spinal cord or spinal nerves in cases in which these structures are approximated. We used hydrodissection in 1 patient with tumor close to the S1 nerve root with instillation of saline around the nerve.

Vertebral cement augmentation was performed for all lytic and mixed osseous tumors $(n=89)$ after technically successful ablation, which was defined by the ability to place the microwave antenna successfully in the center of the lesion and achieve the target ablation power based on the size of the target lesion. No cementation was performed for purely sclerotic lesions. Patients were observed for 3-4 hours in the post anesthesia care unit for any immediate postprocedural complications. Patients were contacted 24-48 hours following their procedures to inquire about their well-being. Any patients who reported new symptoms were brought into the clinic and reviewed.

\section{Statistical Analysis}

Mann-Whitney $U$ tests and graphs were constructed for both ODI and VAS data preprocedurally, against data at 2-4 weeks and 3-6 months, respectively. The data consisted of the following: 69 patients with VAS and 52 patients with ODI scores obtained preprocedurally, at 2-4 weeks, and 20-24 weeks. Ablation time, temperature, energy, and duration of exposure were included as predictors in all models. Marginal plots were then constructed from the mixed models to visually compare the effects of predictors on outcomes. All statistical analyses were completed with GraphPad Prism software 7.0 (GraphPad Software, San Diego, California).

\section{RESULTS}

Technically successful ablations were achieved in 100\% of patients. Technical success was defined as achieving a temperature of $>80^{\circ} \mathrm{C}$, with deposition of calculated energy based on the size of the target lesion with minimal-to-no reverse power.

The median ablation time was 4:30 \pm 0.07 minutes (range, 3:00-10:34 minutes). The median energy dose received was $3.9 \pm$ $1.6 \mathrm{~kJ}$, and power was $13.28 \pm 3.75 \mathrm{~W}$. The preprocedural median VAS score was $7.0 \pm 1.8$. The median postprocedural VAS scores were $2 \pm 1.6$ at $2-4$ weeks and $2 \pm 2.1$ at $20-24$ weeks. A 4-point reduction in the VAS score was considered effective.

Follow-up imaging with CT of the chest, abdomen, and pelvis $(n=34)$ and PET/CT imaging ${ }^{20}$ at 6 months $(n=61)$ demonstrated stable disease in 59/61 patients $(96.7 \%)$. There were 2 procedurerelated complications $(2.9 \%$ ) (S1 nerve thermal injury with the patient having severe pain radiating to the leg in an S1 distribution with three-fifths motor strength, and a skin burn over the target lesion). Eight patients died within 6 months of the procedure.

The median Oswestry Disability Index was $46 \pm 17.9$ preprocedurally and $24 \pm 17.1$ and $24 \pm 18.8$ at 2-4 weeks and 20-24 weeks postprocedurally, respectively. Box-and-whisker plots for VAS and ODI scores are shown in Fig 3.

A median difference of $-22 \pm 12.8$ and $-5 \pm 2.0$ ODI and VAS points, respectively, was observed in the interval between preprocedure (Pre) and 3-6 months postprocedure. Most of the treated patients reported a decreased dosage or frequency of narcotic analgesic use. Changes in the VAS score are demonstrated in Fig 4. Tabular results of Mann-Whitney $U$ paired tests between VAS and ODI data collected preprocedure and at 2-4 and 20-24 weeks are detailed in Table 1.

Locoregional control at 20-24 weeks was achieved in all patients in the subgroup in our series who had oligometastatic disease $(n=22)$. Locoregional control was defined as stable disease at the treated level using a combination of conventional CT, PET/ $\mathrm{CT}$, and spine MR imaging. For the patient to be deemed stable, the imaging study was required to demonstrate the ablation zone encompassing the targeted area of tumor with no evidence of disease progression at the treated site.

Descriptive statistics showing quartiles, median, mean, SD, standard error of the mean, confidence intervals, and mean ranks for each dataset are detailed in Table 2. 

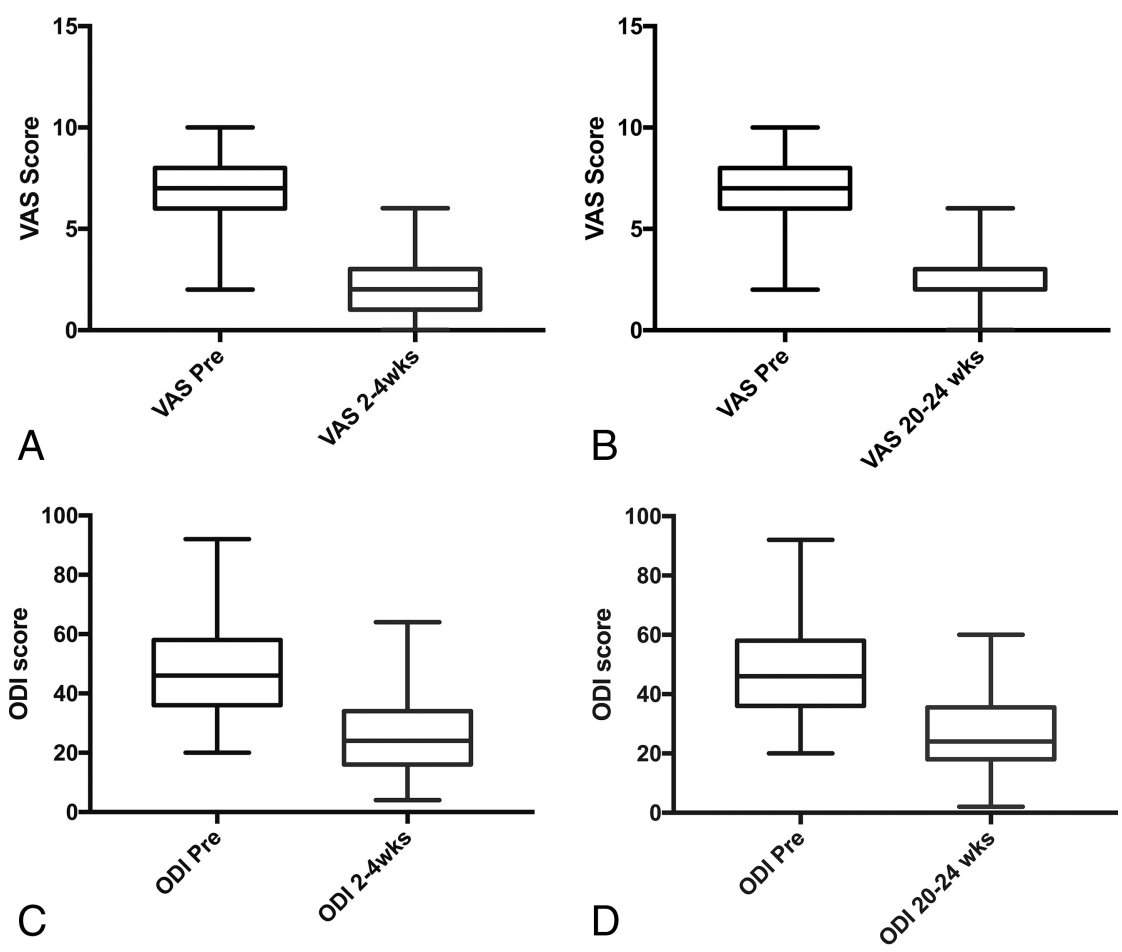

FIG 3. $A$, Box-and-whisker plots for VAS Pre and 2- to 4-week datasets. B, Box-and-whisker plots for VAS Pre and 20- to 24-week datasets. C, Box-and-whisker plots for ODI Pre and 2- to 4-week datasets. D, Box-and-whisker plots for ODI Pre and 20- to 24-week datasets.

\section{DISCUSSION}

As overall survival of cancer patients improves and medical imaging becomes increasingly ubiquitous, the number of patients with osseous metastases continues to grow. Microwave ablation represents a relatively new technique in the minimally invasive armamentarium that will likely play an increasing role in the palliative and potentially curative treatment of patients with painful spinal metastases. With this in mind, we reviewed results of microwave ablation and cementoplasty at our institution in the context of the existing scientific literature.

Microwave ablation of tumor cells is primarily achieved using electromagnetic methods, resulting in tumor destruction using devices with frequencies ranging between 900 and $2500 \mathrm{MHz}$. Electromagnetic microwaves heat matter by agitating water molecules in the affected and surrounding tissue, producing friction and heat, which induce cellular death via coagulation necrosis. ${ }^{9}$ Microwave ablation is more effective in high-impedance tissues like bone because poor thermal conduction in bone is a limiting factor in radiofrequency ablation. Osseous relative permeability and low conduction help microwaves penetrate deeper and are more effective in thermal ablation compared with radiofrequency ablation.

Radiofrequency ablation, cryoablation, MRI-guided focused ultrasound, and microwave are all being used in clinical practice to treat patients with painful osseous lesions, particularly metastases, for both pain relief and as a useful adjunct therapy for local tumor control. ${ }^{8,10-12}$ The heating of tissues is typically much faster and more precise with microwave ablation and causes better and complete coagulation necrosis. ${ }^{21}$

Clinical evidence for microwave ablation in the spine has been limited to some small series. In a retrospective study, Kastler et $\mathrm{al}^{17}$ reported successfully treating $20 \mathrm{spi}$ nal metastases (17 patients) with MWA (with cementoplasty in 9 cases). They reported pain relief in 16 of 17 patients, with significant pain reduction 1 day, 1 week, 1 month, 3 months, and 6 months after ablation without any major complications.

In a second retrospective study, Pusceddu et $\mathrm{al}^{18}$ reported MWA of 37 osseous metastases (35 patients), which included spinal lesions in 12 patients. Local tumor control was achieved in all patients, and significant pain palliation, 1 week, 1 month, and 6 months after ablation (and 1 year after ablation in surviving patients at that time point). They also reported improved walking ability and no major complications.

In a prospective study, Aubry et $\mathrm{al}^{22}$ reported MWA of 16 bone and soft-tissue lesions in 13 patients. They reported an average necrosis rate of $85 \%$ at the first follow-up, and an $80 \%$ overall success rate; half of these patients were considered complete responders. Local control of the disease persisted with time, though residual disease progressed slowly. Time to recurrence in this study was 7.2 months.

The results of the current study recapitulate the findings in these prior works, with immediate pain reduction obtained in $94 \%(65 / 69)$ of these procedures, maintained for 6 months.

\section{Primary Outcome: Pain Relief}

This series affirms that microwave ablation is a feasible and effective procedure for pain relief in patients with refractory painful spinal metastases. Immediate pain reduction was obtained in $94 \%$ $(65 / 69)$ of these procedures and maintained for $>6$ months.

Reduction in pain from ablation procedures is thought to be attributable to a combination of proposed mechanisms: destruction of pain nerve fibers in the periosteum and bone cortex with reduced pain transmission; reduction in the size of the tumor burden and volume with reduced transmission of pain via the nerve endings; and decreased osteoclastic activity and coagulative necrosis of the tumor cells with a resultant decrease in the production of nerve-stimulating cytokines such as interleukins and $\alpha$-tumor necrosis factor. ${ }^{23}$

There is a significantly increased risk of pathologic fracture following radiation therapy, particularly following stereotactic beam radiation therapy or stereotactic radiosurgery, with a reported incidence of between $15 \%$ and $40 \% .^{24,25}$ Fractures most commonly occur several weeks after radiation and typically involve lytic lesions. ${ }^{26}$ Thus, prophylactic stabilization of these lesions before RT may be useful. Despite the current lack of level 1 evidence to support this practice, we commonly perform vertebral augmentation before RT to prevent fracture-associated morbidities at our institutions. 


\section{Structural Stabilization}

Patients with widely metastatic disease are often systemically unwell and are unable to tolerate prolonged conservative management and all it entails. ${ }^{27}$ Consequently, these patients benefit greatly from early stabilization of fractures, with a lower requirement for bed rest, bracing, and anesthesia. ${ }^{28}$ Even patients with chronic pain from unhealed fractures lasting longer than 12 months can benefit. ${ }^{20}$
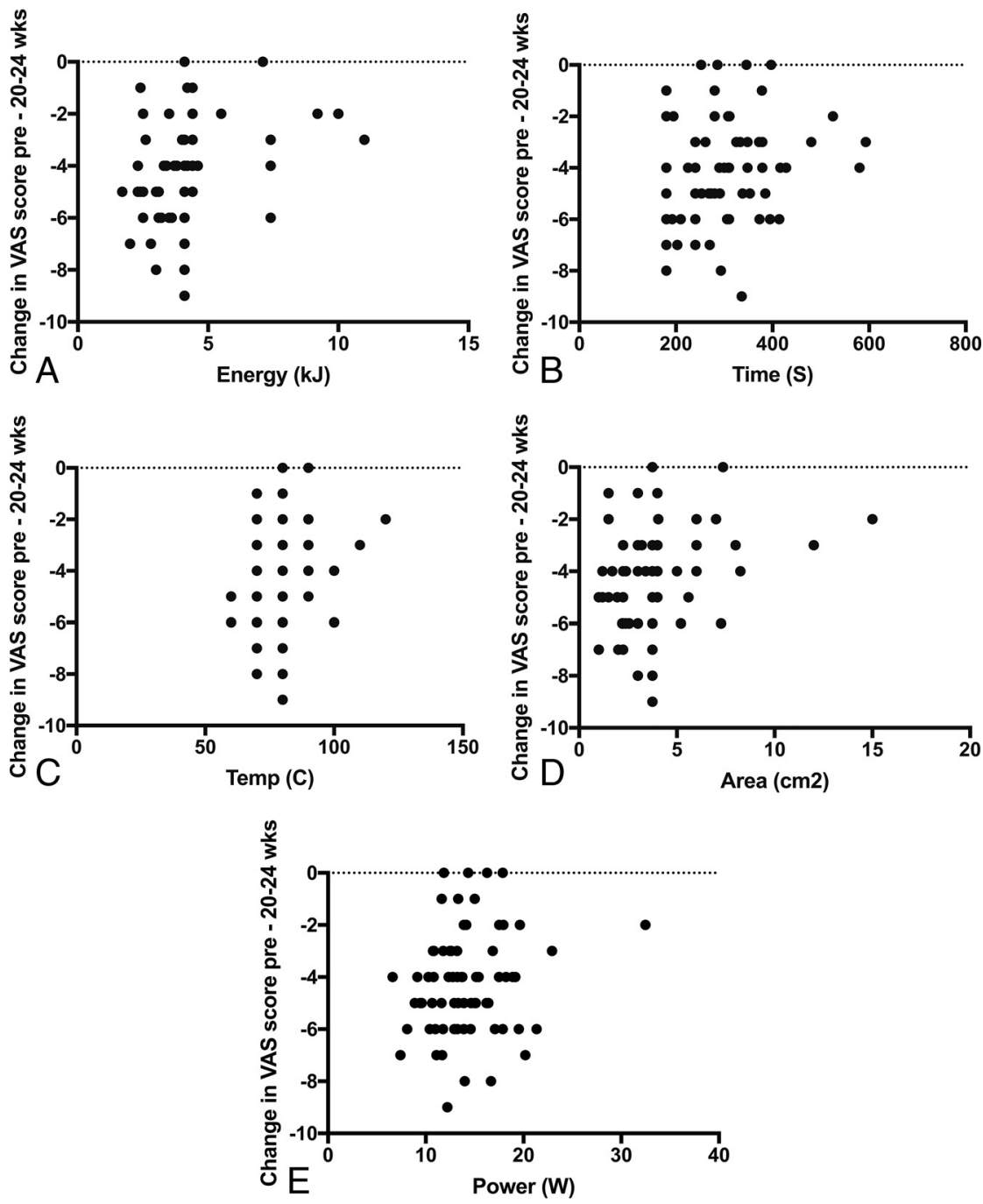

FIG 4. Comparing the change in VAS scores from preprocedure to $20-24$ weeks postprocedure with ablation energy.

Table 2: Descriptive statistics showing quartiles, median, mean, SD, SEM, confidence intervals, and mean ranks for each dataset

\begin{tabular}{|c|c|c|c|c|c|c|}
\hline & VAS Pre & $\begin{array}{l}\text { VAS 2-4 } \\
\text { Weeks }\end{array}$ & $\begin{array}{c}\text { VAS 20-24 } \\
\text { Weeks }\end{array}$ & $\begin{array}{l}\text { ODI } \\
\text { Pre }\end{array}$ & $\begin{array}{l}\text { ODI 2-4 } \\
\text { Weeks }\end{array}$ & $\begin{array}{c}\text { ODI 20-24 } \\
\text { Weeks }\end{array}$ \\
\hline No. of values & 61 & 61 & 61 & 44 & 44 & 44 \\
\hline Minimum & 2 & 0 & 0 & 20 & 4 & 2 \\
\hline $25 \%$ Percentile & 6 & 1 & 2 & 36 & 16 & 18 \\
\hline Median & 7 & 2 & 2 & 46 & 24 & 24 \\
\hline 75\% Percentile & 8 & 3 & 3 & 58 & 34 & 35.5 \\
\hline Maximum & 10 & 6 & 6 & 92 & 64 & 60 \\
\hline Mean & 6.869 & 2.098 & 2.443 & 48.5 & 25.64 & 25.86 \\
\hline SD & 1.737 & 1.338 & 1.522 & 16.37 & 13.78 & 13.18 \\
\hline SEM & 0.2224 & 0.1713 & 0.1949 & 2.469 & 2.077 & 1.988 \\
\hline Lower $95 \% \mathrm{Cl}$ & 6.424 & 1.756 & 2.053 & 43.52 & 21.45 & 21.86 \\
\hline Upper $95 \% \mathrm{Cl}$ & 7.314 & 2.441 & 2.833 & 53.48 & 29.83 & 29.87 \\
\hline Mean ranks & 90.58 & 32.42 & 33.2 & 60.56 & 28.44 & 28.27 \\
\hline
\end{tabular}

Note:-SEM indicates standard error of the mean.
In patients with metastatic disease, surgical decompression has been shown to provide a reasonable long-term ambulatory benefit. Early evaluation for surgical stabilization is therefore recommended, particularly in patients who are young and/or highly functional and have a reasonable long-term prognosis. ${ }^{29,30}$ However, invasive surgery may be inappropriate for frail patients with complex tumors. In addition, prolonged postoperative recovery can delay systemic therapy. ${ }^{31}$

In this group of patients, in whom surgical decompression or fixation or both are inappropriate, there is strong evidence that percutaneous vertebral augmentation can achieve pain relief and functional improvement in both osteoporotic and pathologic fractures.

Cementoplasty (vertebroplasty when performed in the spine and sacroplasty in the sacrum), the injection of polymethylmethacrylate cement, stabilizes axial-loading areas of bone. This stabilization is important because vertebral body collapse after tumor ablation alone has been shown to occur in up to $60 \%$ of patients in the first year following ablation when not combined with cementoplasty support. ${ }^{32}$ Cementoplasty alone does not provide sufficient strength across areas of bone that experience significant sheer or torsional stress. Traditionally, screw fixation would be required to account for such forces. New image-guided percutaneous interventions are currently being developed to facilitate reinforcement in these areas, sometimes termed "osteosynthesis." 33

Vertebral augmentation has been shown to have acceptably low complication rates, quicker recovery times than surgery, and minimal disruption to adjunctive therapies, including chemotherapy and radiation. ${ }^{28,34}$ Patients are typically able to bear weight within a few 
Table 3: Tumor area as defined by largest dimensions in the $\mathrm{x}$ and y planes

\begin{tabular}{lccccc}
\hline & $\begin{array}{c}\text { Energy } \\
(\mathbf{k J})\end{array}$ & $\begin{array}{c}\text { Temperature } \\
\left({ }^{\circ} \mathbf{C}\right)\end{array}$ & $\begin{array}{c}\text { Area } \\
\left(\mathbf{c m}^{2}\right)\end{array}$ & $\begin{array}{c}\text { Time } \\
(\mathbf{s})\end{array}$ & $\begin{array}{c}\text { Power } \\
(\mathbf{W})\end{array}$ \\
\hline No. of values & 102 & 102 & 102 & 102 & 102 \\
Minimum & 1.2 & 60 & 0.75 & 120 & 6.609 \\
25\% Percentile & 2.7 & 70 & 2.25 & 237.5 & 11.22 \\
Median & 4.1 & 80 & 3.57 & 269.5 & 13.28 \\
75\% Percentile & 4.1 & 80 & 3.813 & 336.5 & 15.61 \\
Maximum & 11 & 120 & 15 & 634 & 32.47 \\
Mean & 3.892 & 77.84 & 3.586 & 286.1 & 13.78 \\
SD & 1.604 & 9.584 & 2.218 & 94.41 & 3.75 \\
SEM & 0.1588 & 0.949 & 0.2197 & 9.348 & 0.3713 \\
Lower 95\% Cl & 3.577 & 75.96 & 3.15 & 267.6 & 13.04 \\
Upper 95\% Cl & 4.207 & 79.73 & 4.022 & 304.6 & 14.52 \\
Mean ranks & 235.2 & 478.5 & 207.6 & 580.5 & 374.8 \\
\hline
\end{tabular}

Note:-SEM indicates standard error of the mean.

hours after the procedure and are usually able to engage in physical therapy the following day to minimize further deconditioning. Given the rapid recovery time and absence of large surgical wounds, adjunctive chemotherapy and RT can be rapidly pursued with minimal interruption. With the development of effective adjunctive therapies, tumor regression may often invoke local instability. Vertebral augmentation may therefore also be used to offer stability to vulnerable lesions.

Our findings lend credence to the idea that microwave ablation (in combination with cementoplasty) is effective in achieving effective and durable pain relief and demonstrates an excellent adverse effect profile. Patients who had tumors whose margins approximated nerve roots or the spinal canal were excluded from this study. When these patients are treated, somatosensory-evoked potentials/motor-evoked monitoring is advised to ensure safety.

\section{Secondary Outcome: Tumor Control}

Oligometastatic disease is a unique pathologic state in which patients have limited disseminated disease that may potentially be curable. This model is gaining increasing support within the oncology community and provides justification for treating these patients with an aggressive approach (surgery or embolization). ${ }^{35}$ While many patients have isolated osseous metastases, ${ }^{34}$ surgical resection of osseous lesions is uncommon, likely due to morbidity of the operation. Stereotactic radiation therapy for oligometastases is an active area of investigation, showing promising early results. ${ }^{36-38}$ A few series of image-guided ablation of limited metastatic disease have recently been published, including both exclusively osseous metastases and mixed disease. ${ }^{12,39-42}$

Limited series in the literature show promising local control rates with oligometastatic disease. ${ }^{19,43-46}$ In 1 series, percutaneous thermal ablation of metastatic spine lesions could achieve a reasonable rate of curative therapy (up to $67 \%$ at 1 year ${ }^{12}$ ). This result was achieved in a select subgroup of small, solitary lesions within the vertebral body without significant cortical destruction or posterior element involvement.

Tumor areas in patients in this study are detailed in Table 3. There was a small subset of patients in this study with oligometastatic disease (20/67). Cross-sectional imaging at 20-24 weeks demonstrated no evidence of locoregional progression. Further long-term follow-up would be required to compare this cohort with those described in the literature.

Definitive criteria to select appropriate patients for ablation of oligometastases have not yet been established. Most of the published series include patients with $\leq 5$ sites of metastases. Imageguided ablation is usually used in nonsurgical candidates or in those who develop metastases in a previously irradiated field.

\section{Limitations of the Study}

The study was performed retrospectively on the basis of data from a single institution. Thus, a higher level of evidence could be achieved by performing a prospective, multicenter trial. A definitive record of the patients' medical anesthesia was not kept, which would have potentially provided additional qualification of the effectiveness of therapy. Tumor ablation zones were measured and recorded as areas (rather than volumes). Although this approach may be slightly less accurate, it reflects our current clinical practice and that of several centers with whom we collaborate.

\section{CONCLUSIONS}

Microwave ablation is a promising, safe, and effective treatment for osseous tumors, resulting in both a reduction in pain and a degree of locoregional control of the disease process.

\section{ACKNOWLEDGMENTS}

We are grateful to David Yousem for manuscript revision and mentoring.

Disclosures: Jennifer S. Barr-UNRELATED: Board Membership: Musculoskeletal Transplant Foundation, Comments: member of medical board of trustees; money for my services goes to my institution into a resident funding for books/activities.* *Money paid to the institution.

\section{REFERENCES}

1. Coleman RE. Clinical features of metastatic bone disease and risk of skeletal morbidity. Clin Cancer Res 2006;12:6243s-49s CrossRef Medline

2. Cleeland CS, Gonin R, Hatfield AK, et al. Pain and its treatment in outpatients with metastatic cancer. N Engl J Med 1994;330:592-96 CrossRef Medline

3. Kirou-Mauro AM, Hird A, Wong J, et al. Has pain management in cancer patients with bone metastases improved? A seven-year review at an outpatient palliative radiotherapy clinic. J Pain Symptom Manage 2009;37:77-84 CrossRef Medline

4. Pierik JG, IJzerman MJ, Gaakeer MI, et al. Pain management in the emergency chain: the use and effectiveness of pain management in patients with acute musculoskeletal pain. Pain Med 2015;16:970-84 CrossRef Medline

5. Chow E, Zeng L, Salvo N, et al. Update on the systematic review of palliative radiotherapy trials for bone metastases. Clin Oncol ( $R$ Coll Radiol) 2012;24:112-24 CrossRef Medline

6. Sze WM, Shelley M, Held I, et al. Palliation of metastatic bone pain: single fraction versus multifraction radiotherapy - a systematic review of randomised trials. Clin Oncol (R Coll Radiol) 2003;15:345-52 Medline

7. Wallace AN, Robinson CG, Meyer J, et al. The metastatic spine disease multidisciplinary working group algorithms. Oncologist 2015; 20:1205-15 CrossRef Medline

8. Goldberg SN, Gazelle GS, Mueller PR. Thermal ablation therapy for focal malignancy: a unified approach to underlying principles, techniques, and diagnostic imaging guidance. AJR Am J Roentgenol 2000;174:323-31 CrossRef Medline

9. Simon CJ, Dupuy DE, Mayo-Smith WW. Microwave ablation: prin- 
ciples and applications. Radiographics 2005;25:S69-83 CrossRef Medline

10. Dupuy DE, Goldberg SN. Image-guided radiofrequency tumor ablation: challenges and opportunities-part II. J Vasc Interv Radiol 2001;12:1135-48 CrossRef Medline

11. Kurup AN, Callstrom MR. Increasing role of image-guided ablation in the treatment of musculoskeletal tumors. Cancer J 2016;22: 401-10 CrossRef Medline

12. Deschamps F, Farouil G, Ternes N, et al. Thermal ablation techniques: a curative treatment of bone metastases in selected patients? Eur Radiol 2014;24:1971-80 CrossRef Medline

13. Skinner MG, Iizuka MN, Kolios MC, et al. A theoretical comparison of energy sources-microwave, ultrasound and laser-for interstitial thermal therapy. Phys Med Boil 1998;43:3535-47 CrossRef Medline

14. Stauffer P, Rossetto F, Prakash M, et al. Phantom and animal tissues for modelling the electrical properties of human liver. Int J Hyperthermia 2003;19:89-101 CrossRef Medline

15. Shock SA, Meredith K, Warner TF, et al. Microwave ablation with loop antenna: in vivo porcine liver model. Radiology 2004;231: 143-49 CrossRef Medline

16. Wright AS, Lee FT Jr, Mahvi DM. Hepatic microwave ablation with multiple antennae results in synergistically larger zones of coagulation necrosis. Ann Surg Oncol 2003;10:275-83 CrossRef Medline

17. Kastler A, Alnassan H, Aubry S, et al. Microwave thermal ablation of spinal metastatic bone tumors. J Vasc Interv Radiol 2014;25:1470-75 CrossRef Medline

18. Pusceddu C, Sotgia B, Fele RM, et al. Treatment of bone metastases with microwave thermal ablation. J Vasc Interv Radiol 2013;24: 229-33 CrossRef Medline

19. Kujak JL, Liu PT, Johnson GB, et al. Early experience with percutaneous cryoablation of extra-abdominal desmoid tumors. Skeletal Radiol 2010;39:175-82 CrossRef Medline

20. Brown DB, Gilula LA, Sehgal M, et al. Treatment of chronic symptomatic vertebral compression fractures with percutaneous vertebroplasty. AJR Am J Roentgenol 2004;182:319-22 CrossRef Medline

21. Lubner MG, Brace CL, Hinshaw JL, et al. Microwave tumor ablation: mechanism of action, clinical results, and devices. J Vasc Interv Radiol 2010;21:S192-203 CrossRef Medline

22. Aubry S, Dubut J, Nueffer JP, et al. Prospective 1-year follow-up pilot study of CT-guided microwave ablation in the treatment of bone and soft-tissue malignant tumours. Eur Radiol 2017;27: 1477-85 CrossRef Medline

23. Botsa E, Mylona S, Koutsogiannis I, et al. CT image guided thermal ablation techniques for palliation of painful bone metastases. Ann Palliat Med 2014;3:47-53 CrossRef Medline

24. Jawad MS, Fahim DK, Gerszten PC, et al; on behalf of the Elekta Spine Radiosurgery Research Consortium. Vertebral compression fractures after stereotactic body radiation therapy: a large, multi-institutional, multinational evaluation. J Neurosurg Spine 2016;24: 928-36 CrossRef Medline

25. Rose PS, Laufer I, Boland PJ, et al. Risk of fracture after single fraction image-guided intensity-modulated radiation therapy to spinal metastases. J Clin Oncol 2009;27:5075-79 CrossRef Medline

26. Cunha MV, Al-Omair A, Atenafu EG, et al. Vertebral compression fracture (VCF) after spine stereotactic body radiation therapy (SBRT): analysis of predictive factors. Int J Radiat Oncol Biol Phys 2012;84:e343-49 CrossRef Medline

27. Gold D. The clinical impact of vertebral fractures: quality of life in women with osteoporosis. Bone 1996;18(3 Suppl):185S-89S CrossRef Medline

28. Berenson J, Pflugmacher R, Jarzem P, et al; Cancer Patient Fracture
Evaluation (CAFE) Investigators. Balloon kyphoplasty versus nonsurgical fracture management for treatment of painful vertebral body compression fractures in patients with cancer: a multicentre, randomised controlled trial. Lancet Oncol 2011;12:225-35 CrossRef Medline

29. Leithner A, Gruber G, Hochegger M, et al. Comparison of seven preoperative prognostic scoring systems for spinal metastases. Orthopaedic Proceedings 2010:92-B(Suppl V);602-03

30. Schoenfeld AJ, Le HV, Marjoua Y, et al. Assessing the utility of a clinical prediction score regarding 30-day morbidity and mortality following metastatic spinal surgery: the New England Spinal Metastasis Score (NESMS). Spine J 2016;16:482-90 CrossRef Medline

31. Piccioli A, Spinelli MS, Maccauro G. Impending fracture: a difficult diagnosis. Injury 2014;45:S138-41 CrossRef Medline

32. Wallace AN, Greenwood TJ, Jennings JW. Radiofrequency ablation and vertebral augmentation for palliation of painful spinal metastases. J Neurooncol 2015;124:111-18 CrossRef Medline

33. Deschamps F, de Baere T, Hakime A, et al. Percutaneous osteosynthesis in the pelvis in cancer patients. Eur Radiol 2016;26:1631-39 CrossRef Medline

34. Clark W, Bird P, Gonski P, et al. Safety and efficacy of vertebroplasty for acute painful osteoporotic fractures (VAPOUR): a multicentre, randomised, double-blind, placebo-controlled trial. Lancet 2016; 388:1408-16 CrossRef Medline

35. Weichselbaum RR, Hellman S. Oligometastases revisited. Nat Rev Clin Oncol 2011;8:378-82 CrossRef Medline

36. Lo SS, Teh BS, Mayr NA, et al. Stereotactic body radiation therapy for oligometastases. Discov Med 2010;10:247-54 Medline

37. Milano MT, Katz AW, Muhs AG, et al. A prospective pilot study of curative-intent stereotactic body radiation therapy in patients with 5 or fewer oligometastatic lesions. Cancer 2008;112:650-58 CrossRef Medline

38. Salama JK, Hasselle MD, Chmura SJ, et al. Stereotactic body radiotherapy for multisite extracranial oligometastases: final report of a dose escalation trial in patients with 1 to 5 sites of metastatic disease. Cancer 2012;118:2962-70 CrossRef Medline

39. Barral M, Auperin A, Hakime A, et al. Percutaneous thermal ablation of breast cancer metastases in oligometastatic patients. Cardiovasc Intervent Radiol 2016;39:885-93 CrossRef Medline

40. Littrup PJ, Bang HJ, Currier BP, et al. Soft-tissue cryoablation in diffuse locations: feasibility and intermediate term outcomes. $J$ Vasc Interv Radiol 2013;24:1817-25 CrossRef Medline

41. Solomon LA, Munkarah AR, Vorugu VR, et al. Image-guided percutaneous cryotherapy for the management of gynecologic cancer metastases. Gynecol Oncol 2008;111:202-07 CrossRef Medline

42. Welch BT, Callstrom MR, Carpenter PC, et al. A single-institution experience in image-guided thermal ablation of adrenal gland metastases. J Vasc Interv Radiol 2014;25:593-98 CrossRef Medline

43. McMenomy BP, Kurup AN, Johnson GB, et al. Percutaneous cryoablation of musculoskeletal oligometastatic disease for complete remission. J Vasc Interv Radiol 2013;24:207-13 CrossRef Medline

44. Bang HJ, Littrup PJ, Currier BP, et al. Percutaneous cryoablation of metastatic lesions from non-small-cell lung carcinoma: initial survival, local control, and cost observations. J Vasc Interv Radiol 2012; 23:761-69 CrossRef Medline

45. Bang HJ, Littrup PJ, Goodrich DJ, et al. Percutaneous cryoablation of metastatic renal cell carcinoma for local tumor control: feasibility, outcomes, and estimated cost-effectiveness for palliation. J Vasc Interv Radiol 2012;23:770-77 CrossRef Medline

46. Ilaslan H, Schils J, Joyce M, et al. Radiofrequency ablation: another treatment option for local control of desmoid tumors. Skeletal $R a$ diol 2010;39:169-73 CrossRef Medline 